\title{
Essential oil analysis of coriander plant of Konya region
}

\begin{abstract}
Coriander is a small aromatic perennial herbaceous plant that grows widely in western Asia, India, Pakistan, the Mediterranean basin, and the United States. Although all parts of the plant can be eaten, its fresh leaves and dry seeds are used more, fructose, sucrose), alkaloids, flavones, resins, tannins, anthroquinones, sterols ( $\beta$-stesterol and $\beta$-cytosterelin), and fixed oils. Has a small amount of carminative agent. Coriander plant samples were collected by a specialist pharmacist and phytotherapist (Muammer Sen). Cultured medicinal marshmallow herb flower was harvested and dried. The dried plant was sorted and packed in packages of 50 grams using precision scales. 100 grams of randomly selected samples. It was sent to BATAM laboratory for analysis. The essential oil analysis of the coriander plant of the Konya region has been found in accordance with the pharmacopoeia standards. Coriander plant is used to take advantage of its heavy metal removal feature. Many factors can affect the essential oil ratio of the plant. It is possible to make maximum use of the essential oils of the coriander plant by making the environmental factors suitable.
\end{abstract}

Volume I4 Issue 4 - 202 I

\author{
Hayriye ALP \\ GETAT Center, Necmettin Erbakan University Meram Medical \\ Faculty Hospital, Konya, Turkey
}

\begin{abstract}
Correspondence: Hayriye ALP, GETAT Center, Necmettin Erbakan University Meram Medical Faculty Hospital, Konya, Turkey, Email hayriyebalp@yahoo.com
\end{abstract}

Received: May 05, 202I | Published: July 07, 2021

Keywords: coriander, essential oil, plant, phytotherapeutic

\section{Opinion}

Phytotherapeutic; characterize herbal medicines. Their mechanism of action is clear; they are products that comply with the modern drug definition in accordance with monographs with known safety limits, side effects, contraindications, stability, toxicity limits, and physiological effects. It aims to standardize the part of the plant defined as a drug in accordance with the pharmacopoeias and use its extract, fixed oil, essential oil in treatment.

Traditionally used medicinal plants have inspired the development of many drugs. Traditional herbs can also be used therapeutically in gastrointestinal diseases. The World Health Organization scientifically recommends reliable medicinal plants therapeutically for the treatment of diseases. Natural products derived from medicinal plants, including flavonoids, polyphenols, terpenoids, ${ }^{2}$ saponins, ${ }^{3}$ alkaloids ${ }^{4,5}$ and mucilage lipolysaccharides, ${ }^{4}$ anti-inflammatory, antimicrobial, antiulcer It has great pharmacological importance as antioxidant and anticancer. Plant extracts are generally safe, even at high concentrations.

Coriandrum sativum L. is a medicine and spice plant belonging to the Umbelliferae family, known as coriander, ascot, kuzbere in our country. ${ }^{5}$ In the classification of coriander based on fruit weight and fruit diameter, there are Coriandrum sativum L. whose 1000-grain weight is more than 10 grams and the fruit diameter is greater than $3 \mathrm{~mm}$. sativum, 1000 grain weight less than $10 \mathrm{grams}$ and fruit diameter $3 \mathrm{~mm}$ and smaller Coriandrum sativum L. var. microcarpum DC it is called. ${ }^{6}$

The used part of the plant is its green parts and fruits. Its fruits containing essential oil and fixed oil are used in industry. After the essential oil is extracted, fixed oil can be obtained from the residue obtained by pressing or extraction. Coriander is also an important plant for honey bees and honey production. ${ }^{7}$ In addition to the green herbals of coriander being used as a vegetable and spice, its main part is its fruits. ${ }^{8}$ As its fruits are used directly as spice, the essential oil extracted from the fruits is also used in the food, beverage and perfumery industry. Coriander is a small aromatic perennial herbaceous plant that grows widely in western Asia, India, Pakistan, the Mediterranean basin, and the United States. Although all parts of the plant can be eaten, its fresh leaves and dry seeds are used more, fructose, sucrose), alkaloids, flavones, resins, tannins, anthroquinones, sterols ( $\beta$-stesterol and $\beta$-cytosterelin), and fixed oils. Has a small amount of carminative agent.

Essential oil from different parts, flavonoids, fatty acids, sterols, monoterpenes, -pinenes, limonene, terpinene, p-cymene, borneol, citronellol, camphor, geraniol, coryndrin, dihydrochoryndrin, AE chorionides,-cytosterol, triacontane, trichosantanol, psoralen, angelicin, choriandrinol, $\beta$-sitosterol glucoside, butyl phthalide, Z-ligustilide have been isolated..$^{9,10}$ Volatile components, flavonoids and isocoumarins, make up the main components of coriander. ${ }^{11-13}$ It also contains coriander, vitamins A, B2 (riboflavin), C and dietary fiber. Its most important feature is the use of heavy metal ions from the body. In Greco-Arab traditional medicine, preparations containing coriander seed are used as stimulants, degassing, antispasmodic, diuretic and antirheumatic. Coriander seeds have strong antioxidant properties. Effectiveness has been shown in reducing serum cholesterol as well as reducing serum cholesterol. The remover feature has also been shown in studies. ${ }^{14-16}$

\section{Method}

Coriander plant samples were collected by a specialist pharmacist and phytotherapist (Muammaer Şen). Cultured medicinal marshmallow herb flower was harvested and dried. The dried plant was sorted and packed in packages of 50 grams using precision scales. 100 grams of randomly selected samples. It was sent to AntalyaBATAM laboratory for analysis.

The content analysis of the coriander in the center collected in the table and the ratios that should be in the monograph are given comparatively. 


\section{Result}

The essential oil analysis of the coriander plant of the Konya region has been found in accordance with the pharmacopoeia standards.

\section{Discussion}

In the literature, there are studies conducted with the essential oil ratio of coriander plant. In a study conducted in Van, the rate of essential oil was examined by years. The difference in essential oil ratio between years was not found to be statistically significant. The essential oil ratio was determined as $0.32 \%$ in 2006 and $0.31 \%$ in 2007. It has been found that many factors are effective in obtaining efficiency. In the study, the highest and positive results in terms of thousand grain weight and fruit yield were obtained from Arslan coriander variety, while the highest values were obtained from Gürbüz variety in all other examined yield characteristics. ${ }^{6-8,17}$

In terms of plant density, the highest number of main branches, the number of fruit in the umbrella and the thousand grain weight values were obtained from $50 \mathrm{~cm}$ row spacing, the highest plant height, fruit yield, essential oil ratio, essential oil yield and biological yield values were obtained from $20 \mathrm{~cm}$ row spacing applications has been..$^{6-8} \mathrm{As}$ a result of the research, it was concluded that the Van region is suitable for coriander cultivation and the most suitable coriander variety for the region is Arslan variety and the row spacing is $20 \mathrm{~cm}$.

Many factors can affect the rate of essential oil. Plant genotype is also among the influencing factors: in a study, among the genotypes, Pel-Mus (0.54\%), Gamze and Erbaa varieties $(0.52 \%)$ were the most, Uşak line and Kudret-K varieties $(0.43 \%$ and $0.45 \%)$ were the least essential oil ratio. It has been determined that they have. According to the analysis, a significant difference was found between locations in terms of essential oil ratio. Accordingly, it has been observed that environmental factors have an effect on the rate of essential oil and the rate of essential oil increases as one goes from the coastal areas to the inner parts. ${ }^{18}$

The planting time of the coriander plant can also affect the essential oil content. According to a study, a significant change was found in plant height, number of umbrellas, number of grains in the main umbrella, thousand kernel weight, essential oil ratio, grain yield and essential oil yield depending on the sowing times. In general, grain yield decreased as the planting time was delayed. It was determined that mid-October plantings with the highest grain yield and essential oil yield were suitable for the region. ${ }^{19}$

\section{Conclusion}

Coriander plant is used to take advantage of its heavy metal removal feature. Many factors can affect the essential oil ratio of the plant. It is possible to make maximum use of the essential oils of the coriander plant by making the environmental factors suitable.

\section{Acknowledgments}

None.

\section{Conflicts of interest}

Author declares there are no conflicts of interest.

\section{Funding}

None.

\section{References}

1. Zeybek AU. Modern and rasionel phytotherapy. Dünya bookstore. 2019. pp. 59

2. Inas ZA, Hala AK, Gehan HH. Gastroprotective effect of Cordia myxa L. fruit extract against indomethacin-induced gastric ulceration in rats. Life Sci J. 2011;8(3):433-445.

3. Awaad AS, El-Meligy RM, Soliman GA. Natural products in treatment of ulcerative colitis and pepticulcer. J Saudi Chem Soc. 2013;17(1):101124.

4. Hage-Sleiman R, Mroueh M, Daher CF. Pharmacological evaluation of aqueous extract of Althaea officinalis flower grown in Lebanon. Pharm Biol. 2011;49(3):327-333.

5. De Sales IRP, Formiga RDO, Machado FDF, et al. Cytoprotective, antioxidant and anti-inflammatory mechanism related to antiulceractivity of Cissampelossympodialis Eichl. In animal models. J Ethnopharmacol. 2018;222:190-200.

6. Baytop T. Treatment with Plants in Turkey. Istanbul Univ. Arrow. No; 3255. Pharm Fak. Arrow. No: 40, Istanbul.

7. Diederichsen A. Promoting the conservation and use of underutilized and neglected crops 3. Coriander, Institute of Plant Genetics and Crop Plant Research. Gatersleben/International Plant. Genetic Resources Inst. 1996. ISBN: 92-9043-284-5.

8. Loaiza J, Cantwell M. Postharvest physiology and quality of cilantro (Coriandrum sativum L.). Hort Science.1997;32(1):104- 407.

9. Momin AH, Acharya SS, Gajjar AV. Coriandrum sativumReview of advances in phytopharmacology. Int J Pharm Sci Res. 2012;3(5):1233.

10. Chen Q, Yao S, Huang X, et al. Supercritical fluid extraction of Coriandrum sativum and subsequent separation of isocoumarins by high-speed counter-current chromatography. Food Chem. 2009;117(3):504-508.

11. Nadeem M, Muhammad Anjum F, Issa Khan M, et al. Nutritional and medicinal aspects of coriander (Coriandrum Sativum L.) A Review. Brit Food J. 2013;115(5):743-755.

12. Paarakh PM. Coriandrum sativum Linn.-Review. Pharmacologyonline. 2009;3:561-573.

13. Sharma V, Kansal L, Sharma A. 2010. Prophylactic efficacy of Coriandrum Sativum (coriander) on testis of lead-exposed mice. Biol Trace Elem Res. 2010;136(3):337-354

14. Saad B, Saad O. Herbal Medicine.In:Greko-Arab and İslamic Herbal Medicine. Hoboken: John Wiley-Sons Inc; 2011. p.47-69.

15. Gosvarni S, Singhai A, Pawar RS. Phytocemical and pharmalogical investigations on coriandrum sativum: a review. Asian J pharma Edu Res. 2012;10-22.

16. Saad B, Saad O. Herbal Medicine. In: Greko-Arab and İslamic Herbal Medicine:Traditional system ethics, safety,efficacy and regulatory issues. Hoboken: John Wiley-Sons Inc; 2011. p. 568.

17. Tunçtürk R. The Effect of Different Sowing Distances on Yield and Quality in Coriandrum sativum L. Kishnish Varieties. Van Centennial Agriculture Magazine. 2011;21(2):89-97.

18. Uzun A, Özçelik H, Özden YŞ. Determination of Some Agricultural Properties of Coriander (Coriandrum sativum L.) Varieties Developed for the Middle Black Sea Region, Yield and Stability Analysis of Essential Oil Ratio. GOÜ. Journal of the Faculty of Agriculture. 2010;27 (1):1-8

19. Özel A. The effect of different sowing times on yield and some vegetative characteristics of coriander (Coriandrum Sativum L.) Under the conditions of the Harran Plain. 2010;13(4):41-48. 